\title{
AGENTE VOLUNTÁRIO AMBIENTAL: UM INSTRUMENTO DE GESTÃO PARA AS UNIDADES DE CONSERVAÇÃO ESTADUAIS DO CEARÁ
}

\author{
Hermógenes Henrique Oliveira Nascimento ${ }^{1}$
}

\section{RESUMO}

O presente trabalho objetiva averiguar como o Agente Voluntário Ambiental contribui na gestão das Unidades de Conservação estaduais do Ceará. O Programa de voluntário foi legalmente instituído pela Secretaria do Meio Ambiente, por meio de Instrução Normativa, possibilitando a sensibilização da comunidade em prol da conservação dos recursos naturais. O serviço voluntário atuante nas Unidades de Conservação é uma forma de aprimorar o manejo e a gestão das atividades significativas, gerando benefícios tanto para o meio ambiente em questão, quanto para o voluntário, em uma oportunidade única de interação e reconciliação entre o homem e a natureza. Com a metodologia adotada, analisou-se a temática do voluntariado ambiental a partir do histórico de outras localidades, além da coleta de dados das atividades dos voluntários. Nesse sentido, foi possível traçar um plano de ação para o monitoramento de todo o trabalho do Programa. Logo, constatou-se que o voluntariado nas Unidades de Conservação é primordial para aumentar o engajamento da sociedade na conservação de áreas verdes protegidas do Estado.

Palavras-chave: Áreas protegidas; Gestão; Voluntariado

\begin{abstract}
The present work aims to investigate how the Environmental Voluntary Agent contributes to the management of the State Conservation Units of Ceará. The Volunteer Program was legally instituted by the Secretariat of the Environment, through a Normative Instruction, enabling the community to sensitize the conservation of natural resources. Voluntary service in the Conservation Units is a way to improve the management and management of significant activities, generating benefits both for the environment in question and for the volunteer, in a unique opportunity for interaction and reconciliation between man and nature. With the methodology adopted, the environmental volunteer theme was analyzed based on the history of other localities, as well as data collection of volunteer activities. In this sense, it was possible to draw up a plan of action for the monitoring of all the work of the Program. Therefore, it was found that volunteering in Conservation Units is essential to increase society's commitment to the conservation of protected areas of the State.
\end{abstract}

Keywords: Protected areas; Management; Volunteering

\section{INTRODUÇÃO}

Um dos principais temas que ganha ampla atenção da comunidade internacional para a formulação de políticas públicas ambientais está relacionado com a biodiversidade, o que tem levado debate sobre os processos necessários para a conservação da diversidade biológica do mundo.

${ }^{1}$ Secretaria do Meio Ambiente do Estado do Ceará. E-mail: henrique.sampa@ gmail.com 
As áreas protegidas são mundialmente consideradas como uma estratégia chave para a conservação da biodiversidade e para a provisão de serviços ecossistêmicos. No entanto, as mudanças na relação sociedade e natureza implicaram o avanço das ações antrópicas no ambiente alterando as características físicas, químicas e biológicas do meio. O desafio atual é assegurar que considerável parte da natureza seja protegida.

Outra tendência para a conservação de áreas protegidas ao redor do mundo é o reconhecimento do voluntário como um componente essencial para promover cooperação entre comunidades, encorajar participação de entidades de outros setores e contribuir com a harmonia do uso dos recursos naturais.

Percebe-se que o movimento voluntariado ocorre em qualquer sociedade no mundo. Os termos que o definem e as formas de sua expressão podem variar de acordo com a língua e cultura, mas os valores que o dirigem são comuns e universais: um desejo de contribuir para o bem comum por escolha própria em um espírito de solidariedade, sem esperar remunerações materiais.

Cabe ressaltar que os voluntários são movidos por valores como a justiça, a igualdade e a liberdade, o que já foi expresso na declaração das Nações Unidas. Uma sociedade que oferece assistência e encoraja vários modos de voluntariado também seria apta a promover o bem-estar de seus cidadãos. Uma sociedade que falha em reconhecer e facilitar as contribuições voluntárias priva-se de avanços para atingir o bem-estar social.

É importante preconizar que o conceito de desenvolvimento humano coloca as pessoas exatamente no centro do desenvolvimento. O relatório dos Voluntários das Nações Unidas também adota esse conceito, reconhecendo a importância da realização imaterial para o bemestar individual e social. Melhorias materiais - saúde, educação e trabalhos apropriados continuam essenciais; porém, também vital é a participação e a cidadania ativa das quais os voluntários são expressivos.

O Brasil apresenta uma área com cerca de 8,5 milhões de $\mathrm{km}^{2}$ e cinco biomas muito distintos, e que, segundo o MMA (2011), abriga cerca de 20\% do número total de espécies do planeta Terra. Dentre os compromissos assumidos por parte do Brasil, ficou estabelecida a meta de proteção mínima de $10 \%$ da área de cobertura de cada bioma existente dentro do território brasileiro. Uma das alternativas para a preservação da biodiversidade e conservação dos recursos ambientais é a criação e implantação de áreas protegidas, em especial as Unidades de Conservação (UCs).

Atualmente, o Estado do Ceará possui 23 UCs Estaduais e 01 Corredor Ecológico. O Ceará tem uma grande biodiversidade que compõe o seu patrimônio natural, tanto ao longo dos 573 quilômetros de litoral com dunas, falésias, manguezais, como no sertão de umburanas, pau-d'arco, juremas, angicos e tantos outros exemplares de natureza privilegiada.

Com esse cenário apresentado, a Secretaria do Meio Ambiente (SEMA) integrante da administração direta do Governo do Estado do Ceará, no ano de 2015, publicou normativa que cria o Agente Voluntário Ambiental (AVA) nas UCs estaduais. Assim, a SEMA instituiu 
um programa que tem o objetivo de transformar os voluntários em multiplicadores das ações de proteção e gestão das UC.

As competências desta Secretaria são de elaborar, planejar e implementar a política ambiental do Estado; monitorar, avaliar e executar a política ambiental do Estado; promover a articulação interinstitucional de cunho ambiental nos âmbitos federal, estadual e municipal; propor, gerir e coordenar a implantação de UCs sob jurisdição estadual; coordenar planos, programas e projetos de educação ambiental; dentre outros atributos.

A maioria das áreas de conservação estaduais é composta por unidades de Uso Sustentável. Com o novo cenário do Sistema Estadual de Unidades de Conservação, que expandiu e vem protegendo áreas de grande relevância para a conservação da biodiversidade da Caatinga e a manutenção de recursos naturais, surgiu à necessidade de uma melhor consolidação das bases legais e do conjunto de normas e procedimentos que definissem e amparassem as ações de implementação das UCs.

O cenário técnico nas estratégias de gestão das UCs precisava ser de fato legitimado, de forma que essa evolução fosse não somente reconhecida, como também servisse de referência para o fortalecimento das políticas públicas de gestão de UCs do Estado do Ceará.

O objetivo desse trabalho é analisar como o Programa de Agente Voluntário Ambiental contribui para o fortalecimento da gestão das UCs estaduais da Secretaria do Meio Ambiente.

\section{METODOLOGIA}

A metodologia científica pode ser compreendida, de forma resumida, como a soma de técnicas e processos empregados na realização de uma pesquisa, sendo que as técnicas corresponderiam às atividades sistematizadas e racionais que permitem alcançar os objetivos, delineando o caminho metodológico a ser seguido (MARCONI; LAKATOS, 2003).

Nesse sentido, foram duas técnicas empregadas nessa pesquisa:

1- Documentação indireta: refere-se ao levantamento de dados em fontes primárias e secundárias através de:

- Pesquisa documental: realizada no acervo histórico de voluntarismo em áreas protegidas, onde foi possível ter acesso aos arquivos e dados estatísticos sobre o assunto.

- Pesquisa bibliográfica: baseou-se no levantamento, análise e interpretação de obras pertinentes ao tema, a partir de quatro eixos principais:

I - Voluntarismo, II - Unidades de Conservação, III - Gestão, IV - Educação Ambiental

2 - Documentação direta: correspondeu ao levantamento de dados produzidos pelos próprios voluntários mensalmente através de relatórios de atividades que são executadas nas UCs contempladas pelo Programa. 


\section{O VOLUNTARIADO E AS ÁREAS PROTEGIDAS}

O voluntariado é uma das expressões mais básicas do comportamento humano e surge das antigas tradições de partilha e trocas mútuas, que há muito tempo já foram estabelecidas. No seu núcleo estão os relacionamentos e o seu potencial para engrandecer o bem-estar dos indivíduos e da comunidade. A coesão social e a confiança, por exemplo, prosperam onde o voluntariado é prevalente.

O voluntariado não é apenas a coluna vertebral das organizações da sociedade civil, social e dos movimentos políticos, mas também da saúde, educação, habitação e programas ambientais e uma série de outros segmentos da sociedade, programas do setor público e privado em todo o mundo. É uma parte integrante de toda a sociedade. A história do voluntariado confunde-se com a própria história das ações dos indivíduos em relação aos seus semelhantes. Alguns autores, como Hudson (1999) avaliam essa história sob o ponto de vista de todo um segmento dedicado a causas sociais.

Em muitas comunidades ao redor do mundo, sistemas estão profundamente enraizados, caracterizados pela solidariedade, compaixão, empatia e respeito pelos outros, muitas vezes expressos por meio da doação de tempo. $\mathrm{O}$ voluntariado também expressa o desejo de agir nos sentimentos de justiça e imparcialidade diante da desigualdade e promover a harmonia social, baseado em um interesse comum no bem-estar da comunidade. Na maioria dos idiomas, há palavras que expressam o conceito de voluntariado. Frequentemente inspirado pelas tradições indígenas, elas descrevem os principais caminhos pelos quais as pessoas coletivamente aplicam suas energias, talentos, conhecimentos e outros recursos para o benefício mútuo. $\mathrm{O}$ ato de voluntariar-se é bem conhecido por todo o mundo, mesmo que a palavra não seja.

O serviço voluntário em parques nacionais é uma tradição em inúmeros países do mundo. Nos Estados Unidos, o Serviço de Parques Nacionais (National Park Service) conta com um programa de voluntários que gera benefícios mútuos para os parques e para os voluntários. A cada ano mais de 120.000 voluntários doam mais de 4 milhões de horas em serviço nos Parques Nacionais americanos.

Em parques nacionais chilenos, australianos e sul-africanos os voluntários são os principais responsáveis pela manutenção dos sistemas de trilhas e por realizar trabalhos educativos com os visitantes. Na Itália a ONG WWF conta com mais de 35 anos de atividades e grande quantidade de voluntários permanentes e ocasionais para atividades voluntárias diversificadas nos parques e reservas.

Em Parques Nacionais, o trabalho voluntário vem sendo uma tradição em vários países, como Estados Unidos Itália e Nova Zelândia, estes voluntários são responsáveis pela manutenção dos sistemas de trilhas e atividades educativos perante aos visitantes. Há estudos de caso sobre voluntariado em áreas protegidas pelo Departamento de Conservação da Nova Zelândia, que faz um apontamento de que a ferramenta utilizada pela equipe responsável pelo 
gerenciamento das atividades voluntárias nas áreas protegidas é de total diferença ao desempenho da atividade (USA, 1994).

Os colaboradores atuam com alto grau de receptividade junto aos voluntários, sendo compreensíveis, pacientes e detalhistas sobre as explicações para que os mesmos saibam exatamente no que estão participando e qual a atividade que poderão desenvolver nos locais onde permanecerão como voluntários (SOUZA, 2007).

Este modelo comprova uma questão muito importante na efetivação de programas de voluntariado em áreas protegidas, sobre a participação responsável dos colaboradores da área protegida no atendimento aos voluntários de modo a compreender sua importância no desenvolvimento dos trabalhos. O voluntário recebia um certificado de participação e também era presenteado com souvenirs disponíveis para comercialização para os turistas da unidade.

Estas atitudes servem como forma de motivação aos voluntários fazendo com que se sintam parte do processo e contribui no modo como estes se portam frente aos visitantes da UC que atuam. Outro ponto admirável é a existência de um cronograma de orientação detalhada para cada voluntário e cada local, visando respeitar a quantidade de gestores e funcionários nos locais para coordenação e orientação dos voluntários, proporcionando uma valorização destes fazendo com que a presença dos voluntários seja uma experiência positiva para todas as partes envolvidas (SOUZA, 2007).

Na Austrália, país que desenvolve ações de voluntariado em áreas protegidas, existe a organização Conservation Volunteers Australia, que atua desde 1982 na missão de "atrair e gerenciar uma força de voluntários em projetos de conservação em práticas para a melhoria do meio ambiente australiano" (CONSERVATION, 2009). Anualmente, esta organização recebe cerca de 10.000 voluntários, tanto locais como estrangeiros, que atuam em mais 2.000 projetos em espaços protegidos da Austrália e Nova Zelândia, trabalhando como parceiros junto aos governos federais e estaduais destes países.

Nos EUA, o serviço de proteção aos parques, o National Park Service, realiza sua parceria com as tribos indígenas, estados, governos locais, colonizadores, ONGs e outros que se dispõem a contribuir voluntariamente com a preservação desde locais. Na Califórnia há uma forte atuação de voluntários no desenvolvimento de atividades nos parques estaduais. Os voluntários auxiliam em quase todas as atividades das áreas protegidas como orientação aos visitantes, educação ambiental, manutenção de instalações, segurança, gestão de recursos naturais e culturais entre outras.

É plausível afirmar com base nos modelos acima citado, que a atividade voluntária desenvolvida em áreas protegidas não é algo novo nem desconhecido. Há programas eficazes que com o passar do tempo foram implantados apresentam resultados positivos correlacionados à atuação dos voluntários nas áreas protegidas, resguardando nas atividades cotidianas, enriquecendo em forma conhecimentos dos visitantes e contribuindo com os aspectos conservacionistas e valorativos das áreas protegida. 


\section{VOLUNTARIADO EM ÁREAS PROTEGIDAS NO BRASIL}

No Brasil, as áreas protegidas eram consideradas espaços que deveriam ser isoladas de qualquer atividade humana, ficando à margem ou no caminho do processo de desenvolvimento. Essa visão provocou um cenário no qual poucos brasileiros se interessavam em visitar e conhecer essas áreas, gerando então, uma consequente falta de entendimento da importância de se manter tais espaços preservados e conservados (MMA 2002).

Aqui, trabalho voluntário foi regularizado pela Lei Federal no 9.608/98. Segundo esta lei, o serviço voluntário é uma atividade não remunerada, prestada por pessoa física a entidade pública de qualquer natureza, ou a instituição privada sem fins lucrativos que tenha objetivos cívicos, culturais, educacionais, científicos, recreativos ou de assistência social inclusive a mutualidade. O serviço voluntário não gera vínculo empregatício nem obrigação de natureza trabalhista previdenciária ou afim.

Uma ideia central do serviço é o fortalecimento da gestão e do manejo através do trabalho voluntário, segundo a ideologia inspiradora de gestão participativa do Sistema Nacional de Unidades de Conservação (SNUC). De acordo com a Lei do SNUC (N ${ }^{\circ}$ 9.985/2000) em seu Artigo $5^{\circ}$ “O SNUC será regido por diretrizes que: (..) III - assegurem a participação efetiva das populações locais na criação, implantação e gestão das unidades de conservação"; (...).

O Ministério do Meio Ambiente (MMA), no ano de 2002, como iniciativa ao fomento da atividade voluntária, realizou o primeiro Seminário Internacional "Voluntários nos Parques do Brasil: Conduta Consciente, Ética e Cidadania", promovido pela Diretoria das Áreas Protegidas, da Secretaria de Biodiversidade e Florestas, em parceria com o Conselho do Programa de Comunidade Solidária.

A proposta de voluntários em UCs é, de forma mais ampla, atrair a população para um trabalho integrado de gestão, tendo como finalidade levá-lo a uma tomada de consciência de que a UC é um bem público, a serviço e a cuidados de todos. A concepção disso envolve um processo de educação ambiental a ser expandido para todos os visitantes, fazendo com que esses percebam que a conduta consciente na UC, já é por si só, um ato voluntário em defesa dos recursos naturais.

\section{VOLUNTARIADO EM UNIDADES DE CONSERVAÇÃO DO ESTADO DO CEARÁ}

O trabalho voluntário em UCs do Estado do Ceará pode ser uma importante ferramenta para a democratização da gestão da unidade, possibilitando um maior envolvimento da população na preservação dos recursos naturais de forma sincera, consciente e espontânea. Através do engajamento dos voluntários garante-se um comprometimento com a causa ambiental e um auxílio importante nos serviços de manutenção da UC, incentivando a proteção das áreas naturais para gerações presentes e futuras.

No início de 2015, o Programa de Agente Voluntário Ambiental foi estruturado legalmente com a expedição de uma IN e a partir dessa formalização, deu-se início às ações 
de lançamento de edital de chamamento, divulgação, seleção de candidatos e todo o processo de cadastramento e convocação dos aprovados. Por meio de uma análise da demanda para o trabalho voluntário e a necessidade interna da SEMA foi realizada uma priorização das atividades voluntárias que seriam ofertadas nas seguintes UCs: Parque Estadual do Cocó, Parque Estadual Botânico, Parque Estadual do Sítio Fundão, Estação Ecológica do Pecém, APA da Serra de Baturité, APA da Bica do Ipu e na Célula de Conservação da Diversidade Biológica - CEDIB.

As atividades priorizadas para esse primeiro edital foram: prestação de informações aos visitantes; desenvolvimento de projetos de educação ambiental e pesquisa; manutenção de trilhas e instalações; apoio às populações do entorno; desenvolvimento de trabalhos administrativos; auxilio na brigada de incêndios; apoio na busca e resgate; recuperação de áreas degradadas; e auxílio na implementação de projetos de manejo das UC.

A seleção foi realizada levando em consideração o conhecimento e a experiência do candidato correspondente à atividade escolhida, bem como aos trabalhos em andamento na UC. Os critérios adotados estavam na análise do currículo e da ficha cadastral, como também desempenho em entrevista. Os candidatos que estavam aptos a concorrer às vagas eram maiores de 18 anos e foi dada preferência aos moradores do entorno da UC, estudantes universitários com no mínimo 03 (três) semestres de curso em andamento, graduados e pósgraduados nas áreas de turismo, ciências biológicas, ciências da terra, ciências sociais, ciências agrárias e demais afins.

Pode-se concluir que este Programa está sendo bem sucedido em vários aspectos, dentre eles: a efetiva participação cidadã de voluntários (moradores do entorno) em atividades de conservação e conscientização na UC; a parceria com importantes órgãos públicos e Universidades; além de continuar tendo uma boa repercussão nos meios de comunicação através de várias matérias e reportagens na TV, jornais e redes sociais. Destaca-se que as atividades do programa de voluntários têm contribuído para o encaminhamento de estratégias de solução para uma série de problemas e conflitos ambientais nas UCs do Estado do Ceará.

\section{CONCLUSÃO}

Como se vê, está crescendo o reconhecimento da necessidade de mudar nossa produção insustentável e nossos padrões de consumo. Isso requer vontade política e apoio e adesão dos cidadãos. Voluntariado não é o remédio para todos os males, porém, é um componente essencial de qualquer estratégia que reconhece que progresso não pode ser medido por retorno financeiro e que os indivíduos não são motivados por interesses próprios, mas também pelos seus valores e convicções.

Assim, é importante que a experiência bem sucedida do Programa AVA se espalhe para outras UCs estaduais do Ceará. Com novas iniciativas e demandas que se multiplicam, cada vez mais pessoas se juntam à causa do meio ambiente e passam a exercer sua cidadania ambiental e a cuidar das áreas protegidas do Estado. 


\section{REFERÊNCIAS}

CONSERVATION VOLUNTEERS AUSTRALIA. What we do. Jul. 2017. Disponível em: <http://conservationvolunteers.com.au/> Acesso: 10/07/2017.

HUDSON, M. Administrando organizações do terceiro setor. São Paulo: Makron Books, 1999.

LAKATOS, E. M.; MARCONI, M. de A. Fundamentos de metodologia científica. 5. ed. São Paulo: Atlas, 2003.

MINISTÉRIO DO MEIO AMBIENTE. Dez Anos do sistema nacional de unidades de conservação da natureza: lições do passado, realizações presentes e perspectivas para o futuro. Brasília: Ministério do Meio Ambiente. 1. Ed, 2011. 220p.

Planejamento e Operação de Programas de Voluntariado em Unidades de Conservação. Brasília: MMA/SBF/DAP, 2002. 44 p.

SOUZA, C. A. Voluntariado em áreas protegidas: estudo de caso do Department of Conservation na Nova Zelândia. Foz do Iguaçu, 2007.

USA- National Park Service. Volunteers in parks. Washington, DC, 1994. 